MATEC Web of Conferences 22,04029 (2015)

DOI: $10.1051 /$ matecconf/ 20152204029

(C) Owned by the authors, published by EDP Sciences, 2015

\title{
Experimental Study on Post Grouting Bearing Capacity of Large Diam- eter Bored Piles
}

\author{
Duanduan Wang*, Longfei Wang \& Lipeng Zhang \\ College of Highway, Chang'an University, Xi'an, Shaanxi, China
}

\begin{abstract}
Post grouting can improve the inherent defects such as the formation of the mud cake at pile side and the sediment at pile end in the process of bored pile construction. Thus post grouting has been widely used in Engineering. The purpose of this paper is to research the influences of post grouting to pile bearing capacity more systematically and intuitively. Combined with the static load test of four test piles in Weihe River Bridge test area of new airport highway in Xi' an, the bearing capacity and settlement of routine piles and post grouting piles are comparatively analyzed. The test results show that under the same geological condition, post grouting can improve the properties of pile tip and pile shaft soil of bored piles significantly, enhance the ultimate resistance, improve the ultimate bearing capacity and reduce the pile tip settlement. Then post grouting can aim to optimize pile foundation.
\end{abstract}

Keywords: bored pile; post grouting; settlement; bearing capacity; pile shaft resistance; pile tip resistance

\section{INTRODUCTION}

The large bridge engineering has a high request to bridge pile foundation because the upper load is huge. The construction technology of bored pile is mature and reliable currently. Therefore, it has been vastly used in large bridge engineering. But it has some inherent disadvantages such as the existence of sediment at the hole bottom and pile lateral slurry cake, and they will decrease the bearing capacity of single pile through influencing pile tip resistance and pile shaft resistance in different degree. The sediment of large diameter pile at the hole bottom and pile lateral slurry cake is very obvious in loess area because of the characteristics which include loess's macrospore and vertical joint development. Post grouting technology is one of methods to solve these problems and now it has been recognized gradually and been used commonly. Post grouting is a new technology which has developed against the traditional constructive technology. After the concrete strength of bored pile has achieved a certain level, and the pile is conducted post grouting. Through the grouting pipe, the cement slurry arrivals to the pile tip. Thus the negative effect of pile tip sediment and pile shaft mud cake is eliminated. And the condition of pile-soil interaction is improved so that the pile bearing capacity is increased. This paper proves that post-grouting technology can increase ultimate bearing capacity of single pile and decrease settlement to reach a purpose of optimizing pile length, saving investment and reducing cost. This paper analyzes the post-grouting technology's influence to pile tip resistance, pile shaft resistance and ultimate bearing capacity by combing with four test piles' static loading test of High-speed Weihe super large bridge of new airport highway in Xi'an.

*Corresponding author: wangduanduan11@163.com

\section{INTRODUCTION TO THE TEST}

\subsection{Experimental design}

Based on the results of drilling and investigation of engineering geology, the formation in exploration area is loose quaternary sediments. In test area, the upper formation is new loess soil, loam, sandy loam, and sand grain in regional. The lower formation is new underground continuous wall, medium coarse sand, gravel sand, in the middle of formation have some pieces of lensing loam and sandy loam. The formation distribution in test area is familiar to engineering region. The stratigraphic layering is shown in Table 1.

Table 1. Stratigraphic distribution table

\begin{tabular}{llll}
\hline Stratum & $\begin{array}{l}\text { Formation } \\
\text { thickness/kPa }\end{array}$ & $\begin{array}{l}\text { Allowable } \\
\text { bearing } \\
\text { capacity/kPa }\end{array}$ & $\begin{array}{l}\text { Ultimate } \\
\text { resistance/kPa }\end{array}$ \\
\hline $\begin{array}{l}\text { Medium } \\
\text { sand }\end{array}$ & 8.00 & 250 & 45 \\
$\begin{array}{l}\text { Medium } \\
\text { sand }\end{array}$ & 2.00 & 350 & 50 \\
$\begin{array}{l}\text { Coarse } \\
\text { sand }\end{array}$ & 3.70 & 400 & 75 \\
$\begin{array}{l}\text { Sub clay } \\
\text { Coarse }\end{array}$ & 1.50 & 130 & 50 \\
sand & 5.20 & 410 & 75 \\
$\begin{array}{l}\text { Medium } \\
\text { sand }\end{array}$ & 6.80 & 400 & 55 \\
\hline
\end{tabular}

The test area has four test piles (S1 S4), among which, S1 and S2 are routine piles, and S3 and S4 are grouting piles. There are ten anchor piles (M1 M10) in test area. The test pile length is $25 \mathrm{~m}$ and pile diam- 


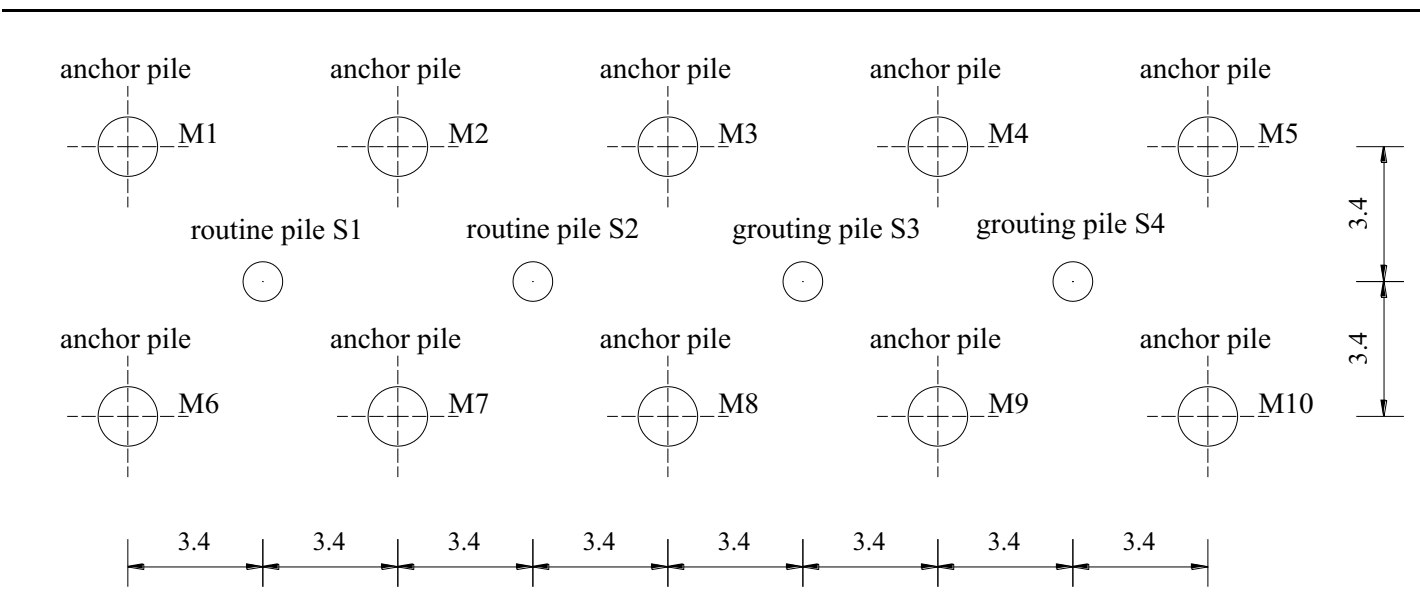

Figure 1. Arrangement chart of test piles and anchor piles eter is $1.3 \mathrm{~m}$. Anchor pile length is $36 \mathrm{~m}$ and pile diameter is $1.5 \mathrm{~m}$. The arrangement is shown in Figure1. This test requires test pile to be destroyed by load, and four test piles' maximum load is shown in Table 2 .

Table 2. The maximum load estimates of test piles

\begin{tabular}{lll}
\hline Test piles & S1\&S2 & S3\&S4 \\
\hline Pile diameter/m & 1.3 & 1.3 \\
Pile length/m & 25 & 25 \\
The maximum load estimates/kN & 13742 & 28669 \\
\hline
\end{tabular}

\subsection{Test method}

The test of vertical bearing capacity of single pile uses anchor pile cross beam reactive device through slow loading methods namely step loading. The next load should be applied when previous load come to stable until to the end of loading condition. Then unload gradually by every $2000 \mathrm{kN}$ one step. By using four orthogonal array percent meter $20 \mathrm{~cm}$ up to pile top to measure pile foundation settlement and using sliding micrometer to measure internal force of pile in the test. The data should be recorded after $5 \mathrm{~min}, 10 \mathrm{~min}$, and $15 \mathrm{~min}$ later after every load applied, and then record every $15 \mathrm{~min}$. One hour later, the data should be recorded every $30 \mathrm{~min}$ in test record form. The test can apply next load when pile foundation's settlement rate less than $0.1 \mathrm{~mm} / \mathrm{h}$. It can be seen as satisfied with the relative standard settlement. This test use reinforcement meter to collect axial force of pile. The test chooses JXG-1 reinforcement meter in which diameter is $22 \mathrm{~mm}$ as force measurement element based on main reinforcement type of test pile. The reinforcement meter can be used after calibration by biaxial tension-compression. The rage of reinforcement meter is $40 \mathrm{kN}$ (tension) and $60 \mathrm{kN}$ (compression). The arrangement of reinforcement meter is decided by test pile's soil layer distribution and embedded depth; every test section need arrange three reinforcement meters.
The test piles S3 and S4 are post grouting piles. There are one grouting pipe at pile side and three grouting pipes at pile tip. The circumferential grouting valve at pile side is decorated at the distance of $15 \mathrm{~m}$ to the pile top. The grouting valve at pile tip is beyond the bottom of steel reinforcement cage $10 \mathrm{~cm}$ and the grouting pipes are professional pipes for grouting.

\subsection{Experimental principle}

By using four orthogonal array percent meter $20 \mathrm{~cm}$ up to pile top to measure pile foundation settlement and using sliding micrometer to measure internal force of pile in the test, pile deformation test and settlement observation should be carried out simultaneously.

According to the strain at the zero point of fitting curve under each load, it can be used to calculate the average elastic modulus under different strain. The E-curve can be got from linear regression, namely:

$E_{i}=E_{0}-K \varepsilon_{i}$

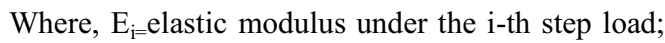
$\mathrm{E}_{0}=$ elastic modulus at the zero point of fitting curve; $\mathrm{K}=$ correction coefficient; $\varepsilon_{i}=$ strain under the $\mathrm{i}$-th step load.

Axial force of pile is:

$N_{i}=A_{i} E_{i} \varepsilon_{i}$

Where, $\mathrm{N}_{\mathrm{i}}=$ axial force of pile under the i-th step load; $\mathrm{A}_{\mathrm{i}}=$ section area of pile body; $\mathrm{E}_{\mathrm{i}}=$ elastic modulus of pile body; $\varepsilon_{i}=$ strain of pile body.

Pile shaft resistance can be calculated from axial force of pile difference between two adjacent sections and the formation's pile side surface area.

$q_{i k}=\frac{N_{i}-N_{i-1}}{S_{i} \cdot L_{i}}$

Where, $\mathrm{q}_{\mathrm{ki}}=$ pile shaft resistance of the $\mathrm{i}$-th section; $\mathrm{N}_{\mathrm{i}}=$ axial force of pile of $\mathrm{i}$-th section; $\mathrm{N}_{\mathrm{i}-1}=$ axial force of pile of (i-1)-th section; $S_{i}=$ the pile perimeter of the $i$-th section; $L_{i}=$ the length of the $i$-th section. 


\section{ANALYSIS OF TEST RESULTS}

3.1 Characteristics of single pile's ultimate bearing capacity

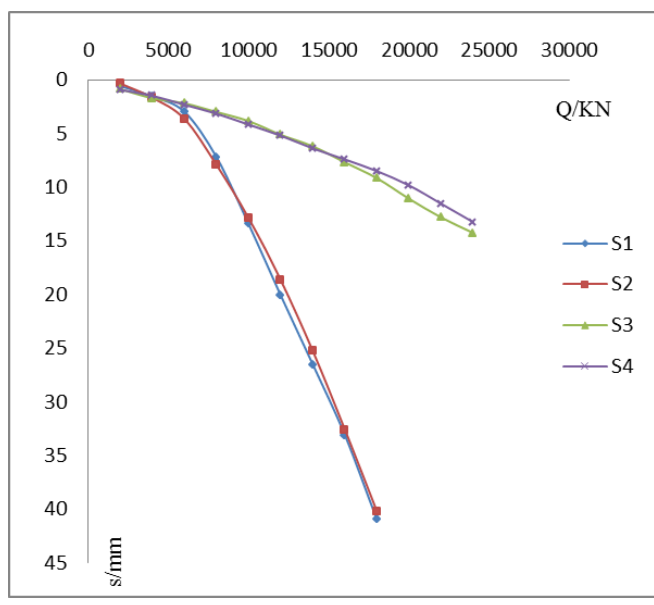

Figure 2. Load and settlements curves of test piles

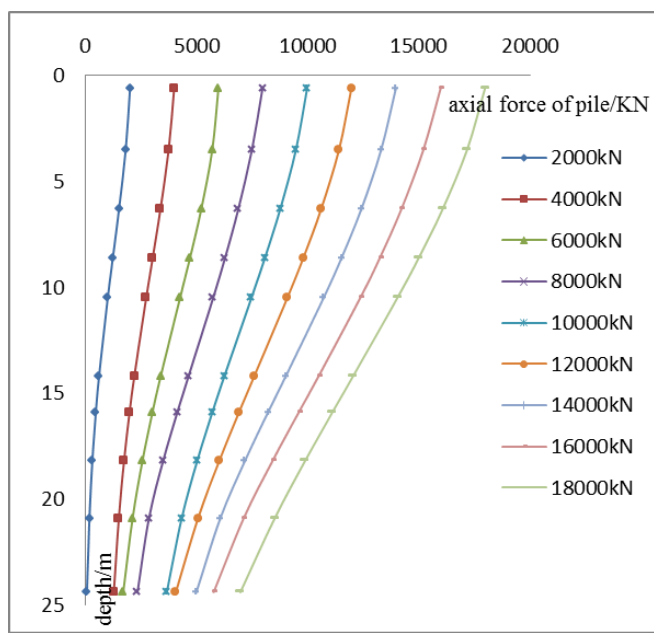

Figure 3. Distribution curves of axial force of pile S1

The pile ultimate bearing capacity is the limit value of load in the pile foundation static load test, and it also can be reflected by the settlement at the top of the test pile in the experiment. Through the static load test of four test piles, the comparison of load-bearing capacity between conventional piles and grouting piles by the pile Q-S curve in Figure 2. Four load-settlement curves of piles show a slower variant, there is no obvious turning points. The loading amount of the test piles $\mathrm{S} 1, \mathrm{~S} 2$ is $18000 \mathrm{kN}$, and the maximum settlement of the two test piles are respectively $40.969 \mathrm{~mm}$, $40.198 \mathrm{~mm}$. The loading amount of the test piles S3 and S4 is $26000 \mathrm{kN}$, and the maximum settlement of the two test piles are respectively $14.256 \mathrm{~mm}$, $13.249 \mathrm{~mm}$. Obviously, the ultimate bearing capacity of single pile compares with the ordinary pile improved by $44.4 \%$, and the largest settlement is reduced significantly by using grouting process of pile bottom.

\subsection{Comparative analysis of load transfer behavior}

The load transfer behavior of four test piles is similar. Take the test piles S1 and S3 for example. Axial force of pile transfer down gradually with the increasing of load. The value of axial force of pile reduces gradually with the embedded depth increasing. The value of pile tip resistance increases with the load increasing. Pile shaft resistance plays gradually from pile top to bottom, and its play degree increases gradually with the adding of load.

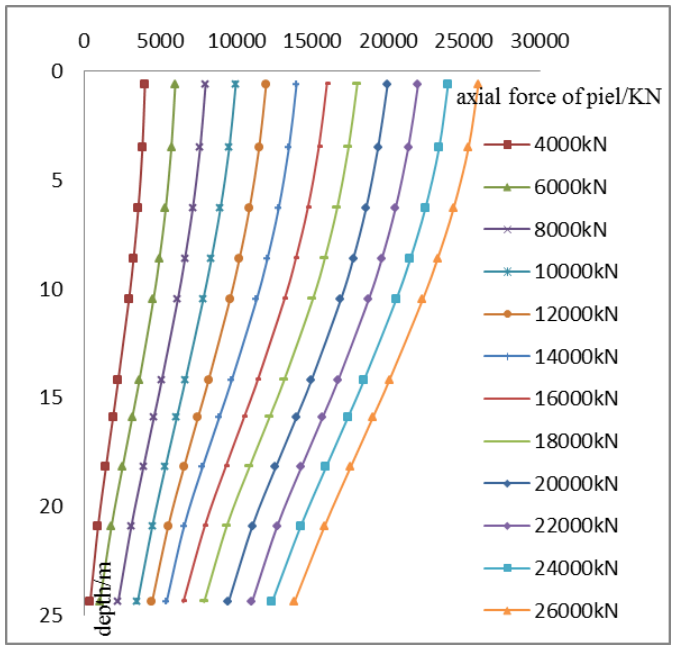

Figure 4. Distribution curves of axial force of pile S3

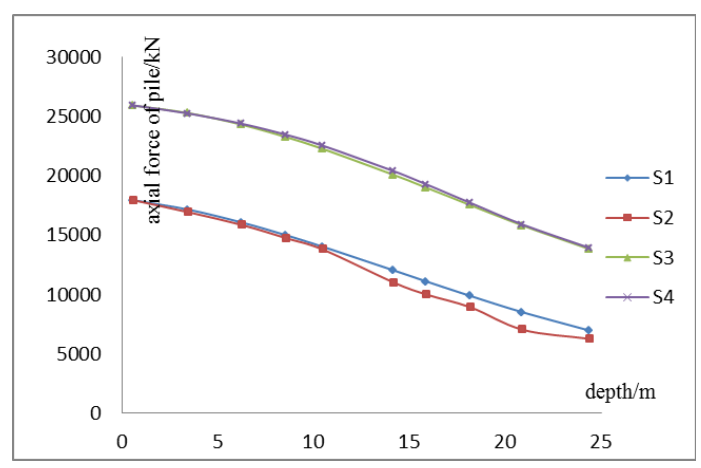

Figure 5. Distribution curves of axial force of piles under ultimate load

Comparatively analyzing Figure 3 and Figure 4, it 
can be seen that the decay rate of axial force of post grouting pile is faster than the routine piles. And its value is adding with the increasing of depth, which shows that the difference of axial force of pile section and the pile shaft resistance are big. Figure 5 shows the distribution curve of piles shaft resistance under the ultimate load. It can be seen that under the same condition of soil layer and construction technology, the distribution behavior of axial force of piles is similar. Through comparatively analyzing the routine piles and post grouting piles, the load transfer behaviors are similar, but the bearing capacity of single pile is increased greatly by post grouting. Thus the axial force of post grouting piles is higher than routine piles.

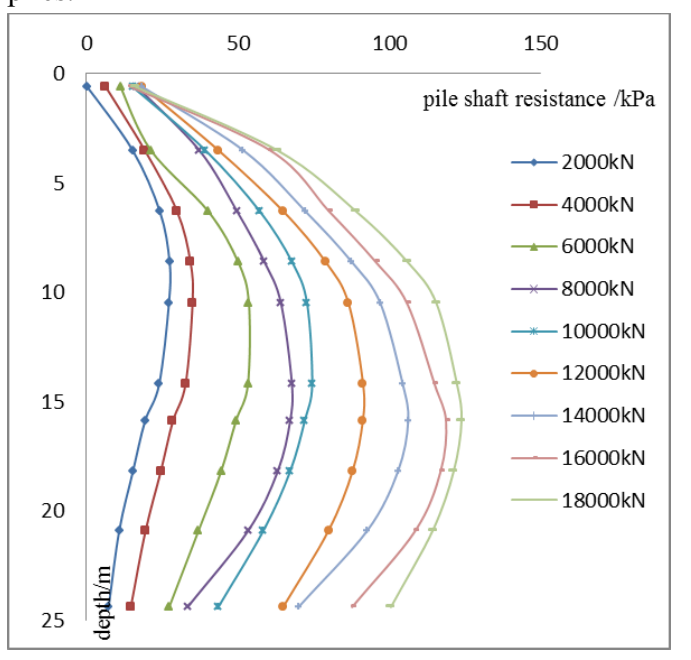

Figure 6. Distribution curve of pile S1 shaft resistance

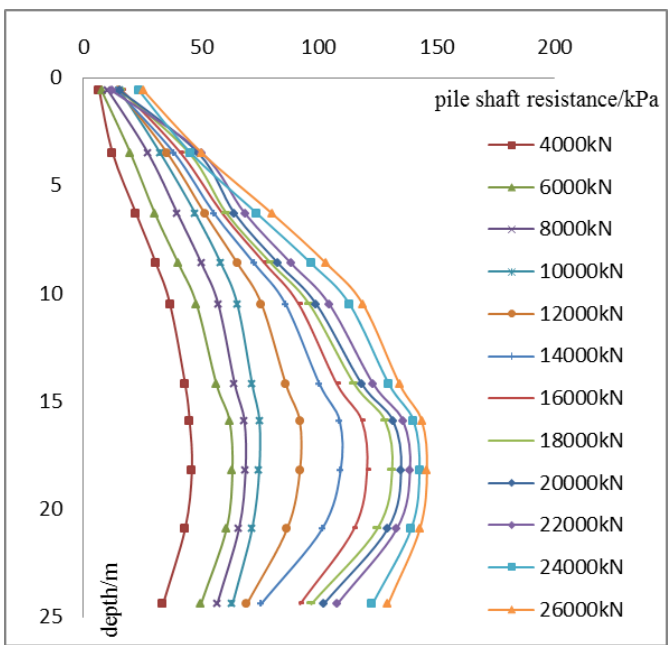

Figure 7. Distribution curve of pile S3 shaft resistance

Take the test pile S1 and S3 for an example, pile tip load transferred from two test piles are $6960 \mathrm{kN}$, $13822 \mathrm{kN}$. Axial force of pile transferred from post grouting pile $\mathrm{S} 3$ is about 2 times than routine pile $\mathrm{S} 1$. The ultimate bearing capacity of single test pile S3 is 1.4 times bigger than test pile S1. Therefore, the ratio in pile tip soil's bearing capacity has an obvious increase under the influence of post grouting.

\subsection{Action of pile shaft and pile tip resistance}

Figure 6 and Figure 7 are test pile S1 and test pile S3's distribution curve of piles shaft resistance. The pile shaft resistance of two test piles both have single peak in the curve. It can be seen in the curve, pile shaft resistance in pile top is almost 0 and it increases with the depth of the pile. Pile shaft resistance can reach peak value in a certain depth, and pile shaft resistance decrease with the increase of depth. It can be seen obviously post grouting pile S3's peak value is lower than routine pile $\mathrm{S} 1$ through the contrastive analysis of distribution curves of two test piles shaft resistance. Post grouting pile S3's peak value is found in $14 \mathrm{~m}$ of pile body, however, routine pile S1 is in $18 \mathrm{~m}$. When reaching peak value, the increase rate of test pile S3 shaft resistance is less than test pile S1. It proves that the property of soil at pile side and end has a huge improvement under the influence of pile end grouting, meanwhile, the ultimate resistance can be developed more adequately.

Table 3. The proportion of pile tip resistance and working load

\begin{tabular}{lllll}
\hline Working load & S1 & S2 & \multicolumn{1}{l}{ S3 } & S4 \\
\hline $2000 \mathrm{kN}$ & $3.1 \%$ & $3.9 \%$ & & \\
$4000 \mathrm{kN}$ & $31.75 \%$ & $34.63 \%$ & $9.45 \%$ & $20.55 \%$ \\
$6000 \mathrm{kN}$ & $28.23 \%$ & $18.53 \%$ & $16.88 \%$ & $38.25 \%$ \\
$8000 \mathrm{kN}$ & $29.29 \%$ & $23.86 \%$ & $27.69 \%$ & $49.6 \%$ \\
$10000 \mathrm{kN}$ & $36.52 \%$ & $32.42 \%$ & $34.95 \%$ & $53.44 \%$ \\
$12000 \mathrm{kN}$ & $33.82 \%$ & $32.07 \%$ & $37.07 \%$ & $52.16 \%$ \\
$14000 \mathrm{kN}$ & $35.57 \%$ & $31.03 \%$ & $38.58 \%$ & $53.76 \%$ \\
$16000 \mathrm{kN}$ & $35.99 \%$ & $34.47 \%$ & $40.65 \%$ & $56.26 \%$ \\
$18000 \mathrm{kN}$ & $38.67 \%$ & $34.79 \%$ & $43.86 \%$ & $55.65 \%$ \\
$20000 \mathrm{kN}$ & & & $47.42 \%$ & $58.04 \%$ \\
$22000 \mathrm{kN}$ & & & $50.15 \%$ & $55.65 \%$ \\
$24000 \mathrm{kN}$ & & & $51.48 \%$ & $53.15 \%$ \\
$26000 \mathrm{kN}$ & & & $53.16 \%$ & $53.53 \%$ \\
\hline
\end{tabular}

Table 3 shows the proportion of pile tip resistance and working load. It can be seen obviously that post grouting piles tip resistance is much larger than routine piles'. Under the ultimate load, the propotion of post grouting pile tip resistance and working load is up to more than $50 \%$. The post grouting test piles show the properity of end-support friction pile. And the propotions of toutine pile tip resistance and working load are $38.67 \%, 34.79 \%$ respectively. The routine piles are prone to frictional pile. Table 1 shows that the propotion of test pile S4 tip resistance and working load has researched a high level at the early stage of the static test. The reson for this situation may 
be that it had formed a thick mud cake in the processe of hole, which greatly influenced the play of pile shaft resistance. The mud cake led that the pile tip resistance was mobilized at the initial stage of loading. With the increase of the working load, the pile tip resistance of post grouting pile S3 and S4 is becoming consistent and achieving the approprite level. It can clearly be seen that posting grouting not only improve the proprty of soil at pile tip, but can improve greatly pile shaft resistance.

\subsection{Post grouting mechanism}

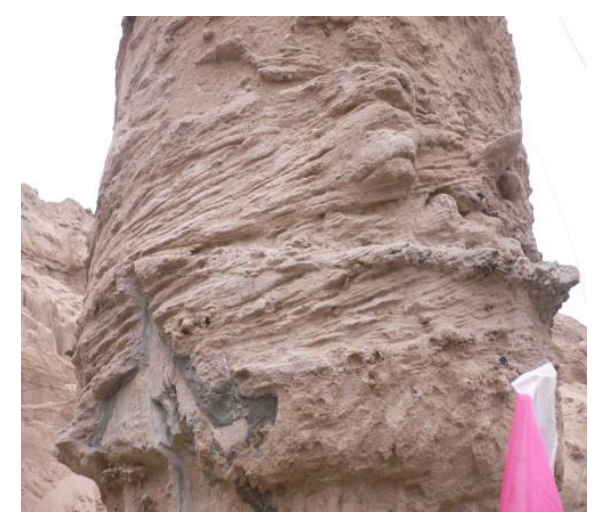

Figure 8. Sectional view of test pile S3

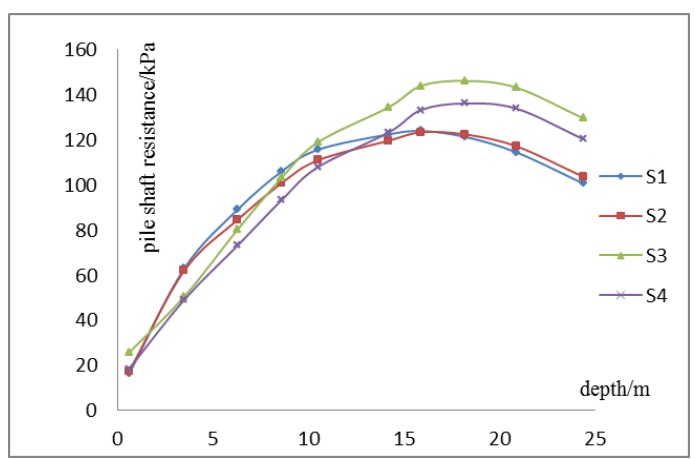

Figure 9. Distribution curves of pile shaft resistance under ultimate load

In the post grouting process for test piles $\mathrm{S} 3$ and $\mathrm{S} 4$, it can be seen that slurry moved up, and overflowed from the soil around test piles. After the static test, the test pile $\mathrm{S} 3$ was excavated. Then it can be seen that the pile body is wrapped with a layer of cement slurry which is about $2 \sim 4 \mathrm{~cm}$. All of this shows the trace of post grouting. Figure 8 is the photo of the test pile S3 excavated.

Figure 9 is the distribution curves of pile shaft resistance under ultimate load. Figure 10 is the relationship between pile tip resistance and load. Due to bot- tom sediment and perturbation of bearing stratum, pile tip resistance of routine piles S1 and S2 have played because of sediment consolidation under a large settlement. Pile tip resistance of post grouting piles S3 and S4 is playing gradually when the pile tip settlement is little. And it is improving fast so that it has a high proportion accounted of pile bearing capacity. Axial force of post grouting piles under the ultimate load is higher significantly than the routine piles', and its ultimate bearing capacity is higher, too. The analysis of post grouting mechanism from pile tip and pile shaft has two aspects.

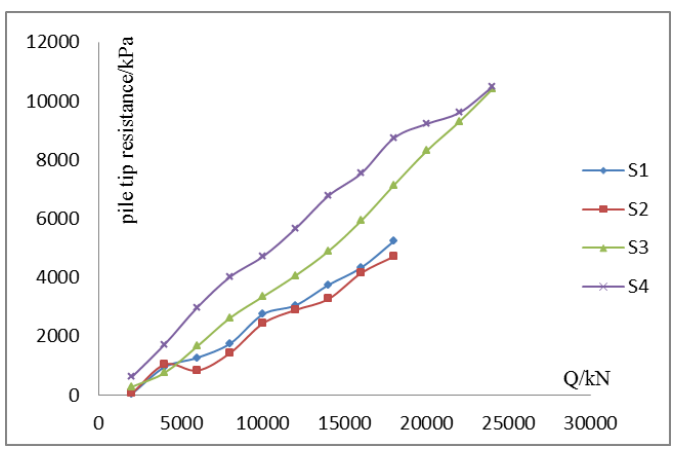

Figure 10. Relationship between pile tip resistance and load

(1) In the construction process of bored pile, a lot of residual sediments in the bottom of hole seriously affect the play of pile tip resistance. For test piles of this project, the pile tip bearing stratum is medium and fine sand, medium coarse sand with gravel, in which void ratio is large. Grouting in this coarse grained soil, the permeability of slurry is high. Through the effect of permeability, filling and compaction of slurry on pile tip soil, the deformation modulus and strength of bearing stratum can be improved significantly. Simultaneously, the slurry forms a pear-expending area, which enlarges the interaction area of pile end, in another word, the stress area becomes larger. So the interaction condition of pile-soil is optimized. After post grouting, a wider range of soil around pile participates the behavior of bearing load. Upper stress can diffuse effectively and strength of pile tip bearing stratum can play fully.

(2) The mud cake of pile side hole wall forms a layer of negative lubricant, which greatly reduces the play of pile shaft resistance. In the grouting process, the slurry under pressure will rise to a certain height along the pile body. The slurry plays a role of compaction replacement and splitting the pile soil and mud cake. Then the original structure of pile-soil interface around pile is changed, and the void of soil and pile-soil is filled. At this time, the interaction between pile and soil is closer and the stress area enlarges, so that pile shaft resistance of lower part of pile can increase greatly. The soil around four test piles in test area is coarse grained soil such as medium and fine 
MATEC Web of Conferences

Table 4. Enhancement factors of shaft and pile tip resistance under post grouting

\begin{tabular}{llllllll}
\hline Stratum & $\begin{array}{l}\text { Silt soil } \\
\text { Mucky } \\
\text { soil }\end{array}$ & $\begin{array}{l}\text { Clay } \\
\text { Silt }\end{array}$ & $\begin{array}{l}\text { Silt sand } \\
\text { Fine sand }\end{array}$ & Medium sand & $\begin{array}{l}\text { Coarse sand } \\
\text { Gravel sand }\end{array}$ & $\begin{array}{l}\text { Gravel } \\
\text { Pebble }\end{array}$ & $\begin{array}{l}\text { Complete-weathered rock } \\
\text { Strong-weathered rock }\end{array}$ \\
\hline$\beta_{s i}$ & $1.2 \sim 1.3$ & $1.4 \sim 1.8$ & $1.6 \sim 2.0$ & $1.7 \sim 2.1$ & $2.0 \sim 2.5$ & $2.4 \sim 3.0$ & $1.4 \sim 1.8$ \\
$\beta_{p}$ & & $2.2 \sim 2.5$ & $2.4 \sim 2.8$ & $2.6 \sim 3.0$ & $3.0 \sim 3.5$ & $3.2 \sim 4.0$ & $2.0 \sim 2.4$ \\
\hline
\end{tabular}

Table 5. Enhancement factors of shaft and pile tip resistance under post grouting

\begin{tabular}{lllccccc}
\hline \multirow{2}{*}{ Stratum } & $\begin{array}{l}\text { Clay } \\
\text { Silt }\end{array}$ & Silt sand & Fine sand & Medium sand & Coarse sand & Gravel sand & Gravel soil \\
\hline$\beta_{s i}$ & $1.3 \sim 1.4$ & $1.5 \sim 1.6$ & $1.5 \sim 1.7$ & $1.6 \sim 1.8$ & $1.5 \sim 1.8$ & $1.6 \sim 2.0$ & $1.5 \sim 1.6$ \\
$B_{p}$ & $1.5 \sim 1.8$ & $1.8 \sim 2.0$ & $1.8 \sim 2.1$ & $2.0 \sim 2.3$ & $2.2 \sim 2.4$ & $2.2 \sim 2.4$ & $2.2 \sim 2.5$ \\
\hline
\end{tabular}

sand, medium coarse sand with gravel. Because of post grouting, the soil can be solidification and its shear strength can be increased, and then pile shaft resistance can play better.

\section{EXISTED DESIGNING INTRODUCTION OF POST GROUTING PILE}

Now existing designed introduction of post grouting pile is mostly based on ultimate bearing capacity. This method can make sure ultimate bearing capacity through empirical coefficient. By post grouting, slurry can reinforce pile tip to improve pile tip resistance, meanwhile, slurry upwelling along with the pile-soil interaction to improve pile shaft resistance. It can be concluded that pile tip and pile shaft's post grouting increasing coefficient through large amount of post grouting comparative test, these data can be a reference when designing pile foundation. There are some common methods to design post grouting pile

\subsection{Method of Building Pile Technical Specifications}

The standard value of post grouting pile's ultimate bearing capacity can be estimated by the following formula.

$Q_{u k}=Q_{s k}+Q_{g s k}+Q_{g p k}=u \sum q_{s j k} l_{j}$

$+u \sum \beta_{s i} q_{s i k} l_{g i}+\beta_{p} q_{p k} A_{p}$

Where, $Q_{s k}$ the standard value of full pile shaft resistance which represents post grouting pile's not vertical reinforce part; $Q_{g s k}=$ the standard value of full pile shaft resistance which represents post grouting pile's vertical reinforce part; $Q_{g p k}=$ the standard value of full pile shaft resistance; $u=$ circumference of pile; $l_{j}=j$-th thickness post grouting pile's not vertical reinforce part; $l_{g j}=i$-th thickness post grouting pile's vertical reinforce part. To pound piling pile with hole slurry protected, the length of vertical reinforce part is $12 \mathrm{~m}$ upper to pile tip when it is tip grouting; the length of vertical reinforce part is $12 \mathrm{~m}$ upper to pile tip when it is tip grouting or side and tip combined grouting, while overlap part should be deduced. To vibratory bored pile, the length of vertical reinforce part is $6 \mathrm{~m}$ upper to pile tip when it is tip grouting. $q_{s i k}=$ the ulti- mate shaft resistance of post grouting vertical reinforcement pieces in $i$-th soil layer; $q_{s j k}=$ the origin standard value of ultimate shaft resistance of non-vertical reinforcement pieces in $j$-th soil layer; $q_{p k}=$ the origin standard value of ultimate tip resistance of non-vertical reinforcement pieces in $j$-th soil layer; $\beta_{s i}=$ the enhancement factor of shaft resistance under post grouting; $\beta_{p=}$ the enhancement factor of tip resistance under post grouting. If there is no local value of experience, the enhancement factors can be valued as Table 4

\subsection{Method of Highway Bridge and Culvert Standard}

The ultimate bearing capacity of post grouting pile can be estimated by the following formula.

$\left[R_{a}\right]=\frac{1}{2} u \sum_{i=1}^{n} \beta_{s i} q_{i k} l_{i}+\beta_{p} A_{p} q_{r}$

Where, $\left[R_{a}\right]=$ axial press capacity of single post grouting, and the difference value between dead weight of pile and replaced soil was considered as working load; $\beta_{s i}=$ the enhancement factor of shaft resistance of $i$-th soil layer. It can be chosen as Table 5 . When post grouting is in saturated soil, only the pile shaft resistance which is in the range of $8 \sim 12 \mathrm{~m}$ above pile tip is amended. When post grouting is in unsaturated soil, only the pile shaft resistance which is in the range of $8 \sim 12 \mathrm{~m}$ above pile tip is strengthened and amended. For the non-enhanced scope, $\beta_{s i}=1, \beta_{p=}$ the enhancement factors of tip resistance.

\section{CONCLUSIONS}

(1) Through the infiltration, compaction and other effects on pile tip soil, post grouting technology can effectively improve the bearing capacity of pile tip soil so that pile tip resistance can play better. Another hand, post grouting and the slurry can also compact and replacement soil around pile and combine pile and soil tighter. So that pile shaft resistance improves significantly. The reason of increase of pile shaft resistance and pile tip resistance are both that the stress 
areas of pile and soil are enlarging.

(2) Post grouting technology can improve the inherent defects of bored pile. Then pile shaft resistance and pile tip resistance can play better so that pile ultimate bearing capacity gets a great improvement. The static load test results under the same geological conditions show that the ultimate bearing capacity of post grouting pile can increase $44.4 \%$, and the settlement can reduce significantly.

(3) Post grouting technology of bored piles has a significant effect in the supporting layer of coarse grained soil. For the same load condition, post grouting can deduce pile length, so its construction is simple. Then post grouting technology is economic and reasonable.

\section{REFERENCES}

[1] Dai Guoliang, Gong Weiming \& Cheng Ye, et al. 2005. Application of self-balanced testing and post grouting to large diameter and super-long piles. Chinese Journal of Geotechnical Engineering, 27(6): 690- 694.

[2] Huang Yonglin, Liu Jianda \& Xu Hangang, et al. 2006. Checking distribution of post grouting at bottom of long piles by ultrasonic CT. Chinese Journal of Geotechnical Engineering, 28(9): 1148-1152.

[3] Gong Weiming, Dai Guoliang \& Zhang Haowen. 2007. Test and research on pile-end post-grouting piles technology for super-large bridge pile foundations. Journal of Southeast University (Natural Science Edition), (6): 1066- 1070.

[4] Huang Shenggen \& Gong Weiming. 2006. Study of effect of base grouting on shaft friction of overlength large diameter pile. Rock and Soil Mechanics, 27(5): 711-716.

[5] Qian Rangqing \& Ma Xiuquan. 2006. Application of the post-grouting technique to bridge engineering. Journal of Hefei University of Technology (Natural Science), (5): 573-575.

[6] Zhang Zhongmiao, Wang Huaqiang. \& Zou Jian. 2010. In-situ test and analysis of pile end post grouting in gravel strata with cohesive soils. Chinese Journal of $\mathrm{Ge}$ otechnical Engineering, 32(2): 308-314.

[7] Jiang Jianping, Wang Mingwu. \& Gao Guangyun. 2004. Contrastive study on influence of difference of pile end rock-soil layer on super-long pile. Chinese Journal of Rock Mechanics and Engineering, 23(18): 3190-3195.

[8] Zhang Zhongmiao, Bao Feng. \& Chen Yunmin. 2000 Research on grouted in pile bottom with spherical (columnar) hole expansion theory considering material strain-softening. Chinese Journal of Geotechnical Engineering, 22(2): 243- 246.

[9] HE Jian. 2002. Testing study on vertical bearing properties of cast-in-place pile in muddy rock foundation. Chinese Journal of Rock Mechanics and Engineering, 21(10): 1573-1577.

[10]Zhang Qianqing. \& Zhang Zhongmiao. 2012. Complete load transfer behavior of base-grouted bored pile. Jour- nal of Central South University of Technology, 19: 2037-2046.

[11]Hu Chunlin, Li Xiangdong. \& Wu Zhaohui. 2001. Study of vertical bearing capacity for postgrouting bored pile. Chinese Journal of Rock Mechanics and Engineering, 20(4): 546-550.

[12] Liu Nianwu, Zhang Zhongmiao. \& Zhang Qianqing, et al. 2013. Destructive field tests on mobilization of end resistance of cast-in-situ bored piles. Journal of Central South University of Technology, 20(4): 1071-1078.

[13] Yang Min. 2000. Study of reducing settlement pile foundation based on controlling settlement principle. Chinese Journal of Geotechnical Engineering, 22(4): 481-486.

[14]Zhao Minghua, Liu Qijian. \& Cao Xiren, et al. 2006. Evaluation of vertical bearing capacity of super-long bored single pile by the pile head settlement. Engineering Mechanics, 23(2): 92-96.

[15]Yuan Zhen, Chen Jinjian. \& Wang Jianhua. 2006. Influence of end conditions on load transfer behavior of cast-in-place piles. Rock and Soil Mechanics, 27(8): 1398-1402.

[16]Zhu H. \& Chang M F. 2002. Load transfer curves along bored piles considering modulus degradation... Journal of Geotechnical and Geoenvironmental Engineering Division, 128(9): 764 -774.

[17] Iglauer S. \& Wu Yongfu. 2010. New surfactant classes for enhanced oil recovery and their tertiary oil recovery potential. Journal of Petroleum Science and Engineering, 71: 23-29.

[18]Fang Pengfei, Jiang Ke. \& Zhu Xiangrong, et al. 2009 Comparison test studies on the load bearing characteristics of post-grouted plies in soft soil. Journal of Engineering Geology, 17(2): 280-283.

[19]Zou Jinfeng, An Aijun. \& Deng Zongwei, et al. 2011. Post-grouting in-situ of length bored pile in deep soft regions. Journal of Central South University (Science and Technology), 42(3): 823-828.

[20] Wang Zhongfu, Liu Handong. \& Jia Jinlu, et al. 2012. Experimental study of vertical bearing capacity behavior of large-diameter bored cast-in-situ long pile. Rock and Soil Mechanics, 33(9): 2663-2670. 